\title{
Recepciones del Quijote y temas cervantistas en Yucatán, 1780-1861
}

\section{Receptions of Don Quixote and Cervantine issues in Yucatan, 1780-1861}

\author{
Melchor Campos García* \\ (D) https://orcid.org./0000-0002-0361-3115 \\ Universidad Autónoma de Yucatán, México \\ mcgarcia@correo.uady.mx
}

Resumen: Entre los millares de libros que cruzaron de España hacia tierras americanas, Don Quijote trascendió como lectura de humor, novela ejemplar, en la picaresca, así como en las obras de diversos autores latinoamericanos. Desde una perspectiva regional, el presente ensayo se propone examinar la recepción de la obra en un corpus de textos literarios y discursos históricos publicados en Yucatán entre 1780 y 1861. La exposición se desenvuelve en cuatro líneas de análisis: 1) la respuesta crítica de Pablo Moreno (1841) a la interpretación de Vicente de los Ríos (1780), 2) el recurso del Quijote como modelo para la representación de personajes históricos, donde lectura, locura y utopía se entrelazan, 3) la obra de Cervantes como referente en la literatura burlesca de Don BulleBulle (1847-1848), y 4) el giro en su recepción como una lectura de poca utilidad para la transformación de la sociedad.

Palabras clave: Quijote; cervantismo; recepción; historia; Yucatán.

* Profesor-investigador de la Universidad Autónoma de Yucatán. La presente investigación no contó con ningún tipo de financiamiento.

cómo citar: Campos García, M. (2020). Recepciones del Quijote y temas cervantistas en Yucatán, 17801861. Secuencia (106), e1670. DoI: https://doi.org/10.18234/secuencia.v0i106.1670

cC Esta obra está protegida bajo una Licencia Creative Commons Atribución-NoComercial 4.0 Internacional. 
Abstract: Among the thousands of books that crossed from Spain to the Americas, Don Quixote transcended as a humorous book and an exemplary and picaresque novel, as well as in the works of various Latin American authors. From a regional perspective, this essay seeks to examine the reception of the work in a corpus of literary texts and historical discourses published in Yucatan between 1780 and 1861. It explores four lines of analysis: 1) the critical response of Pablo Moreno (1841) to the interpretation of Vicente de los Ríos (1780), 2) the resource of Don Quixote as a model for the representation of historical figures, in which reading, madness and Utopia are intertwined, 3) the work of Cervantes as a reference in the burlesque literature of Don BulleBulle (1847-1848), and 4) the change in its reception as a reading of little use for the transformation of society.

Key words: Quixote; cervantinism; reception; history; Yucatan.

Recibido: 25 de septiembre de 2018 Aceptado: 4 de marzo de 2019 Publicado: 24 de octubre de 2019

\section{INTRODUCCIÓN}

E n 2015 se cumplieron 400 años de la segunda parte de la "historia" del Quijote dada a la imprenta por Miguel de Cervantes Saavedra (1547-1616). Desde su primera edición (1605) innumerables ejemplares navegaron hacia Nueva España durante todo el periodo colonial y más allá. Entre 1750 y 1778 , de los libros embarcados a Veracruz destaca uno sobre la mayoría de temas religiosos: Don Quijote de la Mancha con 28 registros. Pronto se habría de convertir en un verdadero best seller ya que, en las últimas cuatro décadas de la colonia alcanzaba 67 registros, cuatro por debajo del Año christiano, de J. Croisset (Gómez Álvarez, 2011, pp. 94, 103, 114). La proyección del "Ingenioso hidalgo" en México a partir de Fernando López de Lizardi y otros autores en la geografía americana constata la universalidad de la obra (Hagedorn, 2007, pp. 11-12; Skirius, 1982); no obstante, existen presencias e influencias regionales aún por analizar. En vista de esa popularidad, este artículo se propone, desde la historia cultural, contribuir a desentrañar la presencia, recepción y manejo de 
algunos temas cervantistas en un corpus de textos yucatecos publicados en la prensa política y literaria, sin incluir las novelas yucatecas.

El periodo de estudio inicia en 1780, año de la espléndida edición del Quijote por la Real Academia Española, ${ }^{1}$ punto de emergencia del cervantismo (Rey Hazas y Muñoz Sánchez, 2006, pp. 54-55), y cierra en 1861, momento de crisis en la recepción como libro de humor y "novela ejemplar", así como de la idealización del héroe en el último tercio del siglo XVIII (Rivero Iglesias, 2011).

La presencia del Quijote en Yucatán puede rastrearse a partir de algunas ediciones conservadas en distintos acervos locales. Un preciado ejemplar de 1608, que comprende la primera parte de la obra, se encuentra en la Biblioteca Central de la Universidad Autónoma de Yucatán. ${ }^{2}$ En el siglo xVIII, la jerarquía eclesiástica poseía la obra de Cervantes, considerada como una "novela ejemplar" (Ruz Menéndez, 1992, p. 27). También existen evidencias de haber circulado la magnífica edición de 1780, realizada por la RAE, y otra de 1797 editada por Gabriel de Sancha, con un estudio preliminar y una extensa biografía de Cervantes escrita por Juan Antonio Pellicer (Cervantes, 1797). Entre la población yucateca de la época existen dos indicios de la presencia del Quijote: Josefa Barbosa poseía un tomo en octavo mayor; ${ }^{3}$ y el comerciante Luis Sobrino tenía una edición en cinco volúmenes, ${ }^{4}$ posiblemente la de Sancha con el estudio de Pellicer.

Durante 40 años, de 1821 a 1861, El Quijote aparecía con cierta frecuencia en los anuncios periodísticos de venta de libros. Así, en septiembre de 1821, la Imprenta de don Manuel Anguas anunció la venta de El Quijote, en 5 tom[os], ${ }^{5}$ tratándose de la realizada por Sancha. Asimismo, en el ámbito yucateco circuló la impresión mexicana de Mariano Arévalo de $1833,{ }^{6}$ conforme a la edición popular de la RAE de 1782, así como la facsimilar de Masse y Decaen,

${ }^{1}$ En adelante RAE.

${ }^{2}$ Aquella edición se compuso de los 52 primeros capítulos. Cervantes (1608). La edición de 1615 apareció con el título de Segunda Parte del Ingenioso Cavallero Don Qvixote de La Mancha. Madrid, por Iuan de la Cuesta (Cervantes, 1615).

3 Testamentaría de doña Josefa Barbosa, 29 de octubre de 1844. Justicia, Civil, vol. 36, exp. 11. Archivo General del Estado de Yucatán (en adelante AGEY), México.

${ }^{4}$ Testamentaría del Sr. don Luis Sobrino, 10 de octubre de 1860. Justicia, Civil, vol. 92, exp. 13. AGEy, México.

${ }^{5}$ El Yucateco o El Amigo del Pueblo, Mérida, 13 de septiembre de 1821, p. 160.

${ }^{6}$ El ejemplar se encuentra en la Biblioteca Yucatanense de Mérida; perteneció al poeta yucateco Clemente López Trujillo, descendiente de una antigua familia meridana. 
impreso en 1842 por Ignacio Cumplido. ${ }^{7}$ Una década más tarde circuló la edición impresa por la Imprenta de la Voz de la Religión (1852-1853), adornada y publicada por Simón Blanquel. ${ }^{8}$ Casi diez años después, en 1861, la Librería Meridana de Cantón publicitó D. Quijote de la Mancha, en una edición de gran lujo. ${ }^{9}$ De esas ediciones decimonónicas, la más destacada fue la de Madrid con los comentarios de Diego Clemencín (Cervantes, 1833), ya que en las ofertas yucatecas se avisa como el Quijote comentado. ${ }^{10}$

A pesar de esa popularidad, resulta sorprendente que en los periódicos literarios Museo Yucateco (1841-1842) y Registro Yucateco (1845-1846), publicados bajo el liderazgo de Justo Sierra O'Reilly (1814-1861), las referencias a la obra de Cervantes fueran de poca importancia. Al presentar el proyecto del Registro Yucateco, los redactores aludieron al "inmortal autor del Quijote", que no recogió "en vida ni una sola de las flores" de las numerosas coronas dedicadas por la posteridad. ${ }^{11}$ Pero no hubo mención en la reseña de la literatura europea escrita por Vicente Calero (1845) para ese mismo periódico, ya que a vuelo de pájaro mencionó la novela caballeresca en España, para en seguida subrayar la importancia de la literatura italiana por mezclar entretenimiento y utilidad, como rezaba la sentencia de Homero (pp. 67, 68). No obstante, sobresale la crítica elaborada por Pablo Moreno (1841) bajo el título: "Algunas observaciones críticas sobre el Quijote" (pp. 251-254), que Sierra publicó de manera póstuma en el Museo Yucateco; único manuscrito de Moreno (1773-1833) que pasó a la letra impresa y pieza clave en el nacimiento del cervantismo en Yucatán.

\section{EL ANÁLISIS DE VICENTE DE LOS RÍOS}

Aunque no hay certeza del momento en que Moreno escribió su ensayo, en el intervalo de 1780 y 1819, la RAE editó Don Quijote de la Mancha en cuatro ocasiones, pero ninguna como la lujosa edición de 1780 en cuatro volúmenes,

7 En el almacén de D. Julián G. Gutiérrez se hallan en venta las siguientes obras, a precios moderados. El Siglo Diez y Nueve, Mérida, 1 de agosto de 1843, p. 4.

${ }^{8}$ El tomo de esta edición se encuentra en la Biblioteca Yucatanense.

9 Avisos, "Gran colección de novelas y otras obras que se hallan de venta con una gran rebaja de precios en la Librería Meridana”, El Constitucional, Mérida, 6 de noviembre de 1861, p. 4.

10 El Amigo del Pueblo, Mérida, 28 de enero de 1847, p. 4.

${ }^{11}$ Redactores, "Introducción”, Registro Yucateco. Periódico Literario, Mérida, vol. 1, s. d., s. m., 1845 , p. 4. 
además de la económica de 1782 y las de 1787 y $1819 .{ }^{12}$ Cuando Moreno llegó al Seminario como profesor de filosofía en 1802, la famosa edición de lujo tenía ya 22 años de impresa, pero es posible que su crítica la realizara en función de esa primera edición académica, ya que se refiere a la que tenía entre manos como "la magnífica edición de esta obra, esta bellísima producción" (Moreno, 1841, p. 251). Aquella joya que marcó el inicio del cervantismo fue "memorable", "correcta y magnífica" y "en papel especial" con bellos grabados, impresa por Joaquín de Ibarra y precedida entre otros paratextos con un "Juicio crítico o análisis del Quijote” de Ríos (Cervantes, 2005, pp. IX, XII).

Ríos sostuvo que el Quijote era una obra "original y primitiva en su especie", de tal modo que no podía recurrir al recurso de la comparación. Luego entonces, "Cervantes está en el mismo caso que Homero; y las reflexiones que se saquen del arte y método observado por este autor en el Quijote, servirán para juzgar las demás fábulas burlescas" (Ríos, 1780, p. XLIII). Así que procedería del mismo modo que Aristóteles para fundar la prescriptiva de las fábulas heroicas a partir de la Ilíada y la Odisea. El segundo principio consistía en la construcción del héroe manchego con "una sola acción" y "determinado fin" como en las fábulas épicas; aunque se tratara de uno burlesco. Con esa precaución, Ríos (1780) propuso “comparar a Cervantes con Homero" (p. XLIII). Revelando su motivación de situar a Cervantes entre los clásicos (Rey Hazas y Muñoz Sánchez, 2006, p. 57).

Es decir, ambas fueron consideradas como fábulas épicas con la misma finalidad "de todos los fabulistas... instruir deleitando". De manera que la ficción era una máscara que permitía la recepción de la instrucción (Ríos, 1780, p. XLV). Para concluir pronto, Ríos sostenía que el estilo de Cervantes era comparable a Homero, y su "Historia" era un poema épico, en ese sentido, así como la cólera era el carácter de Aquiles, ${ }^{13}$ en el Quijote lo era la locura. Concluyó que la finalidad central de la obra era desterrar los prejuicios ocasionados por las lecturas de la "mala literatura de los libros de caballerías" (Rey Hazas y Muñoz Sánchez, 2006, p. 69; Ríos, 1780, p. cxxiI). El humor fue un medio de utilidad moral: "la corrección de los vicios caballerescos". Ahí

${ }^{12}$ La edición popular de la Academia fue impresa por Joachin de Ibarra en cuatro volúmenes. La tercera edición salió en 1787 en los talleres de la viuda de Ibarra en seis volúmenes. Finalmente, la cuarta edición de 1819 fue publicada por la Imprenta Real. La edición de 1797 no publicó el estudio de Ríos, porque no fue un proyecto de la RAE.

${ }^{13}$ El carácter de acuerdo a Ríos (1780) es la "disposición natural que nos inclina a obrar siempre de un determinado modo" (p. LXIV). 
donde los moralistas habían fracasado en erradicar los libros de caballerías que atentaban contra las costumbres, Cervantes triunfó con la sátira, con ridiculizar dichas obras (Riquer, 2005, pp. LXXIV-LXXV).

\section{UN “LOCO” PROPONE A OTRO “LOCO” COMO HÉROE}

Moreno (1841) inició su crítica sobre una premisa indiscutible, la obra de Cervantes es "la primera de las novelas modernas", y la obra en sí misma "vale por una biblioteca entera”. Pero en seguida lanza la cuestión a tratar: “¿Quién hubiera creído que un tal D. Vicente de los Ríos ha compuesto una luenga, pesada y fastidiosa disertación, que él titula análisis, esforzándose a probar que D. Quijate [sic.] es un poema épico, ni más ni menos que la Ilíada de Homero, o la Eneida de Virgilio?" (p. 251).

Su descontento contra la RAE procedía por haber incluido "tan solemne adefesio" en la extraordinaria edición de 1780. Moreno (1841) reprochó esa desacertada extemporaneidad del juicio de Ríos, ya que, en su opinión, "ni a Cervantes, ni a ninguno de sus coetáneos pasó nunca por la cabeza tan desatinada idea" (p. 251); el autor y los copleros nunca pensaron en que estuvieran haciendo tal cosa: Cervantes nunca pensó en componer una epopeya. La crítica de Moreno a la descontextualización histórica-literaria del Quijote en Ríos es perfectamente válida, ya que fue un error en el que incurrieron muchos críticos ilustrados (Rey Hazas y Muñoz Sánchez, 2006, p. 57).

¿Cuál fue la interpretación literaria de Moreno (1841)? En su opinión, la "novela" de Cervantes consistía en:

[...] una serie de aventuras fundadas todas en la manía del héroe de resucitar la antigua andante caballería, para deshacer tuertos, y enmendar agravios. Como a fuerza de cavilar en la ejecución de su plan ha perdido la cabeza, todo cuanto ve, todo cuanto oye, lo amalgama con las ideas de caballería de que la tiene atestada, y de aquí procede una vena perene de chistes que pueden llamarse de situación, y es la oposición entre lo que realmente son en sí los objetos que se le presentan, y el modo como él los considera (p. 251).

Y en tono burlesco, Moreno (1841) agrega que debería estar "tan loco" Ríos como don Quijote para elevar a un "insensato" - un loco- como protagonista de una epopeya. En cambio, el crítico yucateco propone que Cervantes 
pudo tener presente una máxima de Homero: "el justo se convierte en injusto, y el sabio en loco, cuando se apasiona sobradamente hasta de la propia virtud", y la novela misma sería prueba de esa verdad irrefutable (p. 252).

¿Quién era don Quijote en opinión de Moreno? Un "hombre enojado hasta la más violenta irritación con la humana perversidad, prendado hasta los más estáticos raptos de la virtud y la ideal belleza", pero persuadido que posee fuerza y poder sobrenaturales "para socorrer menesterosos, amparar doncellas, enmendar sin razones, y restituir a la tierra el siglo de oro y el reino de Astrea" (Moreno, 1841, p. 252). Un hombre incapaz de proveerse sus propios alimentos -agregó Moreno-, así como de aceptar los amores ofrecidos por Altisidora y las danzantes de Barcelona. "El desprendimiento de todo interés personal jamás en ningún actor de novela ha llegado hasta el punto que en D. Quijote [...] jamás ha sido verosímil" (Moreno, 1841, p. 252).

Moreno (1841) sostuvo que, con el propósito de desarrollar todo el carácter o personalidad de don Quijote, Cervantes resolvió representarlo "en situaciones diversas, y para esto era indispensable que fueran sus aventuras tan varias como inconexas" (p. 253). De esa estrategia narrativa de representación de situaciones inconexas entre sí, el crítico yucateco concluyó que "la unidad de acción, una de las primeras leyes de la epopeya, se opone diametralmente al plan que en su obra se propuso Cervantes" (p. 253). La observación de que el héroe manchego huyera del peligro fue un trazo de la inconsistencia del carácter del héroe, ya que adolece de las flaquezas humanas. "Pincelada atrevida cuando feliz en una novela, y que sería un defecto inaguantable en una epopeya." "Nunca en Aquiles falta el valor, en Ulises la prudencia, ni la piedad en Eneas; y si Cervantes hubiera contemplado a D. Quijote como héroe de epopeya, no hubiera cometido tan solemne yerro" (p. 253).

La segunda conclusión del crítico yucateco se desprende de la ausencia de un plan previamente trazado, ya que la primera parte fue compuesta sin haber previsto una segunda parte, en consecuencia: "Esta falta de plan que en un poema épico fuera intolerable, deja de serlo en una novela de tal naturale$\mathrm{za}$, que su principal valor, como ya hemos notado, se cifra en la variedad y aun incoherencia de acontecimientos y lances" (p. 253).

Antes de concluir su crítica, Moreno (1841) se detiene a caracterizar la constitución del Quijote, distinguiendo tres componentes: mente, cuerpo y alma. La locura como rasgo del hidalgo caballero fue inversa a su edad y salud física, ya que disminuía en la medida que avanzaban las segundas. En 
la segunda parte de la obra "no siempre es loco, aunque siempre maniático"; sin obsesionarse (pp. 253-254).

El protagonista de la historia muestra otra faceta que Moreno (1841) destacó del Quijote: "la invariable excelencia de su alma, su imperturbable amor de la justicia, su generoso ánimo, sagrario de todas las virtudes sin flaqueza, la actividad de una beneficencia sin tasa”, que no procede de la compasión, sino de otra fuente abundante y pura, "de la obligación... de consagrar todas sus facultades y su vida en beneficio del linaje humano y del reino de la justicia y la virtud en la tierra" (p. 254). Pero su crítica no llegó a plantear el aspecto trágico del héroe cuyos ideales no son alcanzables.

Ahora bien, luego de perfilar la personalidad de don Quijote, el crítico yucateco dirige la mirada hacia Sancho Panza. Un personaje dotado con los hábitos aldeanos, sagaz para descubrir celadas: "Sancho es interesado, malicioso, nada escrupuloso en mentir, ni ser cobarde, huye los peligros," profesando un cariño sincero a su amo (Moreno, 1841, p. 254). Pero lo destacable de la crítica radica en distinguir el humor (lo que mueve a la risa) entre el Quijote y Sancho. En el primero resulta del contraste entre los objetos en sí (la realidad) y la distorsión por la locura (p. 251). Por su parte, "Panza no se propone decir gracias por divertir a las personas [...] todas las respuestas y razones las dice él muy de veras, y no es culpa suya si excitan la risa" (p. 254). Su gracia surge de la confrontación lingüística de su jerga de "rústicos patanes" y "su repentino roce con la de sujetos principales, y su manía de hablar perpetuamente y meterse en todas las conversaciones" (p. 254).

En opinión del mismo yucateco, su empeño en refutar los principios del análisis literario de Ríos podría parecer ridículo ante los "críticos inteligentes", entonces ¿por qué la escribió y al parecer circuló? La motivación radicaba en el espaldarazo de la RAE: "¿Quién se figuraría que la Academia española toda entera hubiese adoptado tan solemne adefesio, y puesto al frente de la magnífica edición de esta obra, esta bellísima producción?" (Moreno, 1841, p. 251).

Moreno contrastó la grandeza de la obra de Cervantes y la lujosa edición con el "adefesio" del estudio de Ríos. El problema envolvía un tema cervantino dirigido a combatir la "extravagancia" de creer todo lo escrito, por el solo hecho de estar impreso con toda formalidad y bajo licencia de una autoridad. En una época donde el respeto a la autoridad aún dominaba las actitudes políticas e intelectuales, la RAE como cuerpo otorgaba su aprobación a la interpretación de Ríos. De otro modo, en caso de haberse publicado como una crítica literaria entre otras, hubiese sido ridículo ocuparse del "disparata- 
do aserto" de Ríos, pero "puede tanto con los más de los lectores la autoridad, [que] se hace forzoso rebatir una idea que una vez admitida estorba que sean apreciadas en lo que realmente valen las inestimables dotes de esta obra inmortal" (Moreno, 1841, p. 253).

\section{QUEMA DE LIBROS Y MANUSCRITOS DE LOS CUERDOS}

La locura del Quijote en vano se quiso remediar con la quema de sus libros de caballería. Sólo la acumulación de los golpes de su andar, en su ya cansado cuerpo le regresó la cordura. Durante la colonia, la Inquisición se encargó de controlar la circulación de libros, castigar a los transgresores y expurgar bibliotecas. Pero de aquella generación de intelectuales yucatecos de fines del siglo xviII, Pablo Moreno y el padre Vicente Ma. Velásquez nada dieron a la imprenta cuando se introdujo a Yucatán desde 1813. Ágrafos no fueron, el enigma radica en que sus manuscritos tuvieron un ardiente final. Antes de morir el padre José Nicolás Lara (1751-1808) quemó "una multitud de legajos manuscritos"; en su caso, Moreno emprendió "varias investigaciones curiosas sobre la historia de nuestro país, y llegó a reunir datos muy preciosos para formarla, purgándola por supuesto, de la inmensa multitud de consejas tradicionales de que bulle" (Turrisa, 1841, p. 5). Sin embargo, luego de una agitada actividad política, el "sabio" yucateco se retiró a la vida doméstica con un rico acervo de materiales propios que no quiso legar "a la posteridad", "ninguna obra, ningún documento, ningún escrito". Otra cosa hubiera sido, agregó Sierra (1841), "si cuando el Sr. Moreno descansaba en la quietud doméstica, se hubiese dedicado a imprimir una multitud de opúsculos, de notas curiosas, la historia antigua de Yucatán que había compuesto, y en una palabra todos sus escritos, sin duda habría añadido una honrosa página a la historia literaria de nuestro país" (p. 20). Pero a su muerte, "una mano fanática hizo desaparecer aquel tesoro" (Turrisa, 1841, p. 5).

¿Por qué Moreno no dio a la imprenta su Historia y otros escritos? En todo caso, no se trataba de trabajos perniciosos. En opinión de Sierra (1841) fue un "descuido imperdonable" que atribuyó a su "demasiada modestia" con repercusiones indeseables (p. 20). Considerando que Moreno conocía las enseñanzas de Cervantes en Don Quijote, ejercía la crítica para distinguir ficción y verdad, historia real/historia ficticia, y practicaba la risa que mueve la 
recepción de las fábulas y consejas en contraste con la realidad, que tan pagado estaba de sí mismo; de modo que la modestia no parece ser una explicación verosímil de su conducta.

El término historia en la época de Cervantes era amplio, sin distinción de narración, novela, crónica, relato, aventura, andanza o biografía; incluso habla de "consejas, cuento o historia" (Cervantes, 2005, pp. 8, 181; Wardropper, 1984). No obstante, Cervantes conocía los problemas que atravesaba el arte de historiar para depurarla de engaños, ficciones, fábulas y extravagancias hasta alcanzar la verdad. Así que parte de su humor radicó en aseverar constantemente que su obra era una historia verdadera (Wardropper, 1984). Veamos que en el episodio del enfrentamiento del Quijote con el "valeroso vizcaíno", se suspendió por falta de información y la creencia de que no "hubiesen sido tan poco curiosos los ingenios de la Mancha que no tuviesen en sus archivos o en sus escritorios algunos papeles que deste famoso caballero tratasen; y así, con esta imaginación, no se desesperó de hallar el fin desta apacible historia, el cual, siéndole el cielo favorable, le halló del modo que se contará" (Cervantes, 2005, p. 83).

Aunque ciertamente estamos frente a una parodia, el problema no radicaba en acudir a dudosas fuentes de primera mano, sino a la falta de crítica. Pues el relator revela que estando en Alcaná de Toledo, un muchacho llegó a vender unos cartapacios y papeles escritos en árabe a un sedero (Cervantes, 2005 , p. 85). Al escuchar algunas líneas ató cabos de que se trataba de la "historia de don Quijote" de la Mancha escrito por Cide Hamete Benengeli, un historiador árabe. ¿Cuál fue la actitud del moro intérprete?, "le abrió por medio, y, leyendo un poco en él, se comenzó a reír" (p. 86). Reír no creer. De lo que trasladó al castellano, el "historiador" separó los asuntos sin importancia; aquellas menudencias de "poca importancia y que no hacen al caso a la verdadera relación de la historia, que ninguna es mala como sea verdadera” (pp. 87-88).

Cervantes (2005) estaba prescribiendo los criterios del arte de historiar: "debiendo ser los historiadores puntuales, verdaderos y nonada apasionados, y que ni el interés ni el miedo, el rencor ni la afición, no les hagan torcer del camino de la verdad, cuya madre es la historia, émula del tiempo, depósito de las acciones, testigo de lo pasado, ejemplo y aviso de lo presente, advertencia de lo por venir" (p. 88). De escribir historia con base en la memoria se mofa en el cuento del pastor relatado por Sancho a don Quijote, quien debía llevar el registro del número de cabras que de una en una pasaba el pescador, de lo contrario -sentenció el narrador- "se acabará el cuento". Y así sucedió. 
"-¿Cómo puede ser eso? -respondió don Quijote-. ¿Tan de esencia de la historia es saber las cabras que han pasado, por extenso, que si se yerra una del número no puedes seguir con la historia?" (Cervantes, 2005, p. 180).

En la conversación de don Quijote con el bachiller Sansón Carrasco acerca de sus acciones puestas en un libro, el hidalgo consideró que la historia humana contiene "altibajos", especialmente la de caballerías. Pero al saber que fueron descritos los "infinitos" palos que le propinaron en distintos encuentros, don Quijote explicó la razón de omitir por equidad, pues ciertas acciones "que ni mudan ni alteran la verdad de la historia no hay para qué escribirlas, si han de redundar en menosprecio del señor de la historia". A lo que el bachiller replicó: "-Así es, pero uno es escribir como poeta, y otro como historiador: el poeta puede contar o cantar las cosas, no como fueron, sino como debían ser; y el historiador las ha de escribir, no como debían ser; sino como fueron, sin añadir ni quitar a la verdad cosa alguna" (Cervantes, 2005, p. 569).

Y en ese mismo sentido del juego del humor sobre la historia verdadera y la ficción, el bachiller califica al libro como "más gustoso y menos perjudicial entretenimiento" por honesto y católico. De otro modo, "-A escribir de otra suerte -dijo don Quijote-, no fuera escribir verdades, sino mentiras, y los historiadores que de mentiras se valen habían de ser quemados como los que hacen moneda falsa"; a más que para componer esas obras se requería "un gran juicio y un maduro entendimiento", ya que la historia "es cosa sagrada, por verdadera, y ahí donde se encontraba la verdad, estaba Dios" (Cervantes, 2005, p. 572). Las crónicas bajo esas prescripciones adolecían de tejer verdades y ficciones como bien sabían los críticos yucatecos desde Moreno hasta Sierra. Así cuando el segundo emprendió el proyecto de imprimir la Historia de Yucatán escrita por fray Diego de Cogolludo en 1688, alertó de sus deficiencias por mezclar hechos documentados con milagros ridículos, hasta extravagantes (cuentos, patrañas y consejas) dignos de romanceros, fanáticos y supersticiosos, pero no para los historiadores del siglo del positivismo. De modo que el editor confiaba en una recepción crítica, y aunque omitió sus fuentes de teoría de la historia, elogió a Cervantes por su lenguaje armonioso y elegante del que carecía Cogolludo. ${ }^{14}$

${ }^{14}$ Y a otros de la época, como Góngora y Quevedo. Justo Sierra, "Bibliografía. Historia de Yucatán por el R. P. Fr. Diego López de Cogolludo”, Registro Yucateco, Mérida, vol. 3, 1846, pp. 241-249. 
Entonces, ¿por qué Moreno prefirió el fuego a la imprenta? El diálogo entre Quijote y Sansón ilustra el problema de dar a la imprenta los manuscritos, y posiblemente permitiría comprender la actitud de Moreno:

No hay libro tan malo -replicó don Quijote-, pero muchas veces acontece que los que tenían méritamente granjeada y alcanzada gran fama por sus escritos, en dándoles a la estampa la perdieron del todo o la menoscabaron en algo.

La causa de eso es -dijo Sansón- que, como las obras impresas se miran despacio, fácilmente se ven sus faltas, y tanto más se escudriñan cuanto es mayor la fama del que las compuso. Los hombres famosos por sus ingenios, los grandes poetas, los ilustres historiadores, siempre o las más veces son envidiados de aquellos que tienen por gusto y por particular entretenimiento juzgar los escritos ajenos sin haber dado algunos propios a la luz del mundo (Cervantes, 2005, p. 573).

Tal vez Moreno guardó sus manuscritos, en especial, sus estudios históricos, por temor a la burla del mismo modo como él sometió a libros y autores, en caso de errores y faltas a la verdad. No obstante, algunos juicios sobre personajes y sucesos de principios del siglo XIX fueron transmitidos oralmente a Justo Sierra O'Reilly, pionero de la novela, el periodismo literario, la biografía y la historia. ${ }^{15}$

\section{LECTURAS DE UN "MONOMANIACO" Y LAS DE UN LOCO JUSTICIERO DE ATAR}

En este apartado me propongo relacionar el tema cervantino para distinguir realidad/ficción y la locura del Quijote como modelo para caracterizar personajes y explicar situaciones históricas en Sierra. La recepción ilustrada de la obra de Cervantes coincidió con la renovación científica y su divulgación en el mundo hispanoamericano. En ese contexto, diversos autores se ocuparon de combatir errores, creencias y supersticiones entre toda clase de gentes, pero de cara a los tropiezos de aquella tarea, se recurrió a la locura del héroe

${ }^{15}$ Para una visión panorámica de Sierra y sus influencias románticas, véase Castro Ibarra (2004), Lara Zavala (2005) y Sol (2014). 
manchego para expresar decepciones y desalientos (Sánchez-Blanco, 2002, pp. 429-442).

En Yucatán, una línea de acción ilustrada fue combatir las consejas del Chilam Balam y sus augurios atemorizantes, "una tradición extravagante y ridícula" para la mirada ilustrada de Sierra; ${ }^{16}$ un error popular perpetuado por algunos que no distinguían la realidad de la ficción. Una tarde de septiembre de 1831, el ilustre yucateco, acompañado de otros jóvenes, acudió ante el padre Zúñiga con el propósito de revelar el misterio del Chilam Balam. El exprofesor del Seminario era un extravagante por su forma de vida, discursos y carácter que, si bien no pasaba por "loco", era considerado un "monomaniaco". Su manía de creerse descendiente de la casa real gótica de España ocupaba "cuatro quintas partes de su tiempo"; y además pretendía demostrar la ilegitimidad de los Borbones con textos bíblicos, Macabeos, Cantar de los Cantares y el libro de Ruth. También lanzaba diatribas contra los indios creyéndolos descendientes de los hebreos, siguiendo las lecturas del Génesis. A pesar de sus manías, Sierra observa otra cara de su personalidad: el padre Zúñiga era un alma caritativa, pacífica, y a pesar de sus "filípicas contra los indios", "no por eso dejaba de manifestarles mucho amor y mucha afabilidad" (Turrisa, 1841, p. 3). Así queda asociada la insania en el ámbito mental conviviendo con la pureza del alma como en don Quijote.

El interés del joven Sierra en el padre Zúñiga radicaba en que guardaba, entre otros documentos, un manuscrito apócrifo maldiciendo a los indígenas que volvieran a sus antiguas idolatrías y en caso de emigrar hacia el Petén Itzá, es decir, en caso de huir en busca de autonomía, les vaticinaba plagas, lluvias de sangre, sequías, langostas y otras desgracias. Luego de estudiar el documento, los jóvenes regresaron con el "monomaniaco" que, al enterarse de las inferencias estudiantiles, reviró:

Pues [i]cómo, nos dijo indignado, se ha podido dudar de la autenticidad de este escrito, que de manos muy respetables ha llegado hasta las mías? ¡Qué poca crítica! Con más conocimientos en el idioma, cualquiera, al leerlo se hubiera convencido de que solo un varón inspirado ha podido usar de un lenguaje tan sublime y misterioso, y cuyos anuncios además, hemos visto desgraciadamente realizados (Turrisa, 1841, p. 5).

\footnotetext{
${ }^{16}$ Sierra escribía bajo el seudónimo de José Turrisa.
} 
Con su crítica literaria y conocimiento del documento, los jóvenes acudieron a Moreno, quien "con una sonrisa irónica" confirmó las opiniones de los muchachos: el manuscrito no era otra "cosa que un tejido de patrañas adrede inventadas" con los fines antes referidos (Turrisa, 1841, p. 5). A diferencia de la lectura del "monomaniaco", Moreno poseía reputación de "un verdadero sabio". La "aplicación constante a la lectura" de Moreno le había infundido calma que podía confundirse con indiferencia. Era un lector crítico y con un manejo profuso de la sátira y la risa. Cuando estudió teología y escritura sagrada -precisó Sierra- quedaba inmerso en sus lecturas "de día y de noche" (de "claro en claro" como el Quijote), pero siempre se le observaba "dibujada en sus labios la invariable sonrisa que lo caracterizaba". Se podía quedar absorto en la lectura sin quedar loco. Moreno se reía de los libros, de la "Biblia y sus comentadores", de los escolásticos del seminario, era un lector escéptico, pirronista, con una destreza en el manejo del ridículo como arma. ${ }^{17}$ Del mismo modo, en la anécdota con el padre Zúñiga, recordó Sierra (Turrisa, 1841, p. 5), los vaticinios del Chilam Balam "nos divirtieron mucho"; el humor (la risa) era la actitud adecuada de contrastar las patrañas (consejas de pastores) con la realidad; no creer y vivir en la ficción.

Es bien sabido que la "locura" del Quijote se desencadena por su obsesión de leer "de claro en claro", libros caballerescos repletos de fantasías y mentiras, ${ }^{18}$ encantamientos y disparates, hasta llegar a afectar "de tal modo en la imaginación que eran verdad[es]" aquellas "soñadas invenciones que leía", como la "historia más cierta en el mundo" (Cervantes, 2005, p. 30). Así, quien fuera tan crédulo o ignorante en creer las fábulas como verdades y actuar en función de esas quimeras era tenido por "loco", como el padre Zúñiga.

Entre la generación de liberales de la primera década del siglo xIx, Moreno imputó esa misma (des)calificación al padre Vicente María Velásquez (1773-1828), fundador de la sociedad sanjuanista. ${ }^{19}$ Pero fue Sierra quien publicó aquella anécdota. Con la sonrisa en los labios, Moreno repetía a todo el mundo que Velásquez "era un loco rematado, a quien por compasión, por

${ }^{17}$ Justo Sierra, "Consideraciones sobre el origen, causas y tendencias de la sublevación de los indígenas, sus probables resultados y su posible remedio", El Fénix, Campeche, 10 de febrero de 1850, pp. 2-3; y 15 de febrero de 1850, p. 2.

${ }^{18}$ Véase el discurso sobre los libros de caballería en el capítulo xxxiI, "Que trata de lo que sucedió en la venta a toda la cuadrilla de don Quijote". Cervantes (2005).

${ }^{19}$ Los sanjuanistas fue una sociabilidad de liberales y partidarios del régimen constitucional español (1810-1814) bajo el liderazgo de Velásquez, rival político de Moreno. 
caridad era preciso encerrarlo en una casa de orates, para que no trasmitiese su perniciosa locura a los demás” ${ }^{20}$ ¿Cuál fue el motivo de aquella severa imputación?

En un contexto de formación del discurso criollo de asumirse como vengadores de los indios conquistados en el siglo XVI, un libro en particular fue señalado como la fuente de los desvaríos del padre Velásquez. Se trataba de la "Destrucción de los indios por los españoles" del padre Bartolomé de Las Casas. El literato campechano expresó su asombro por haber sido Velásquez tan "crédulo hasta la ceguedad", que leyó sin crítica ese "pernicioso libro", una "fábula" "absurda, calumniosa y extravagantísima relación a la cual es imposible prestar asenso". ${ }^{21} \mathrm{La}$ "Destrucción" encendía y enconaba los ánimos criollos contra la conquista, pero del mismo modo que el Quijote, el líder sanjuanista era "amigo del débil y sin apoyo", enemigo de déspotas y tiranos. Un "filántropo capaz de sacrificarse en un arrebato de entusiasmo", que "fortificaba su espíritu preocupado con la funesta lectura" hasta sentir "renacer todo su vigor y energía, y continuaba impávido en un camino que, en su concepto, era el de las reparaciones y el de la justicia". ${ }^{22}$

La insania del padre Velásquez se configura a partir de leer sin criterio una "fábula" que le afectó la cordura, asumir el papel de vengador de los conquistados y perseguir una justicia reparadora, pero anacrónica y aterradora: devolver las tierras a los indígenas y entregar a la mayoría autóctona la facultad de dar las leyes. ${ }^{23}$ Sierra se valió del tema cervantino de la locura del Quijote como modelo para construir un personaje histórico, con rasgos de carácter y comportamiento quijotescos. En otro sentido, de acuerdo con las palabras del propio Ríos, la protección de los nobles para con los "afligidos y menesterosos" no sería extravagante de cumplir con las normas de la equidad y la prudencia, precediendo el "conocimiento de los hechos y de las personas”. Pero entre los nobles de espíritu caballeresco se basaba en el capricho, sin examen, ni fundamento (Ríos, 1780 , p. CII).

20 Sierra, "Consideraciones", El Fénix, 15 de febrero de 1850, p. 3.

${ }^{21}$ Esquivel Pren (1975) sostiene que Cervantes se propuso con insistencia "ayudar a los lectores ignorantes a convertirse en lectores críticos, capaces de distinguir la verdad de las mentiras" (s. p.).

${ }_{22}$ Sierra, "Consideraciones", El Fénix, 20 de noviembre de 1849, pp. 3-4, y 5 de diciembre de 1849 , p. 3.

23 Sierra, “Consideraciones”, El Fénix, 5 de diciembre de 1849, pp. 3-4. 
Moreno era muy crítico, pero formaba parte del entramado de la administración colonial como procurador de Indios, de modo que en el derecho indiano y las instituciones de justicias encontraba los mecanismos legítimos para impartir justicia, no en "extravagancias" extrajurídicas y fuera de las instituciones. Por su parte, Sierra rechazó remedios absurdos a problemas mal diagnosticados, con falsedades y fanatismo.

En una sociedad desgarrada por el conflicto étnico (guerra de castas) que estalló en 1847, el arquetipo del Quijote idealista defensor de los débiles y desprotegidos, emergió de nuevo para descalificar a "defensores de la humanidad", como aquel escritor que denunció la venta de mujeres indígenas a Cuba. En contraparte, las plumas oficialistas justificaron la expulsión como medida humanitaria, en la alternativa de fusilar a los rebeldes capturados. Y en ese caso específico de las apresadas en la costa, sus maridos incursionaron en los pueblos bajo control blanco, asesinando mujeres y niños. De modo que el "humanitario censor" o "filantrópico escritor" fue reconvenido a "entenderse con sus musas, y no cual nuevo D. Quijote meterse a desfacedor [sic.] de agravios y defensor de los enemigos de nuestra raza [blanca]" (Sociedad de Amigos, 1860, p. 11).

\section{LOS NUEVOS QUIJOTES: COMUNISTAS Y SOCIALISTAS}

Desde 1837, Fray Gerundio y Tirabeque emulaban a don Quijote y su escudero Sancho, incluso la prensa satírica jugaba con describir escenas similares a las del Quijote, evocando o refiriendo directamente a los personajes creados por Cervantes como fuentes de sus textos de humor, en situaciones contemporáneas (Fuertes, 2014, pp. 137-140). En uno de sus pasajes propuso dar una lectura satírica a las nuevas utopías en ciernes en Europa: el socialismo y el comunismo. Aquella crítica no pasó desapercibida para los yucatecos editores de la Miscelánea instructiva y amena (1849), quienes la reprodujeron en sus páginas. ${ }^{24}$

Y para el caso, Fray Gerundio, el amo, toma la lectura de lo que le ocurrió al Quijote con los cabreros, en el discurso posterior a una comida:

${ }^{24}$ El artículo que comento titulado "El Quijote de Antaño, y los quijotes de ogaño" fue publicado originalmente en [Fray Gerundio] (1848). 
Dichosa edad, y siglos dichosos aquellos a quien los antiguos pusieron nombre de dorados; y no porque en ellos el oro, que en esta nuestra edad de hierro tanto se estima, se alcanzase en aquella venturosa, sin fatiga alguna, sino porque entonces los que en ella vivían ignoraban estas dos palabras de TUYO Y Mío. Eran en aquella edad todas las cosas comunes [...].

-Pare V. ahí, señor mi amo, me interrumpió Tirabeque. A lo que veo, el señor D. Quijote predicaba ya el comunismo a los cabreros, y esto solo le faltaba para que fuese rematada y completa su locura ([Fray Gerundio], 1849, p. 203).

Y su amo le pide que escuchara otro pasaje de los más hermosos del héroe manchego: "A nadie le era necesario para alcanzar su ordinario sustento tomar otro trabajo que alzar la mano, y alcanzarle de las robustas encinas que liberalmente les estaban convidando con su dulce y sazonado fruto. [...] Todo era paz entonces, todo amistad todo concordia" ([Fray Gerundio], 1849, pp. 203-204). Y continuó su lectura hasta el momento en que revela la llegada de los vicios y para combatirlos se instituyó la orden de los caballeros andantes, "para defender las doncellas, amparar las viudas y socorrer a los huérfanos y menesterosos". De nuevo interrumpe Tirabeque, advirtiendo que el caballero manchego era ya "un socialista de cuatro suelas" por apreciar aquella época donde no había propiedad, ideal que aspiraban los socialistas, y como buen cristiano concluía "que tan Quijotes son los de ogaño como el Quijote de antaño” ([Fray Gerundio], 1849, p. 205).

A todo ello, el amo responde que ambos son reformadores sociales, sólo que los de ahora ya no amparan viudas, damas y huérfanos, sino obreros. Y los antiguos lemas de paz, amistad y concordia fueron sustituidos por los de libertad, igualdad y fraternidad. En seguida procede a destacar de la misma aventura el tema de la igualdad nacida del amor cuando el Quijote dispone que comiere y bebiere en sus mismos trastos, aunque luego se arrepintiera de tanta igualdad.

Pero el amo de esta parodia muestra una diferencia entre la modesta comida del Quijote respecto a los banquetes de los nuevos caballeros andantes, que organizaron por toda Francia para comer con los obreros y predicar "la doctrina de la edad de oro", del mismo modo que cuando el hidalgo comió entre los cabreros. En la mira se encontraba Proudhon y la revolución de 1848, con una característica más grave: el ateísmo. A lo que el sirviente Tirabeque contesta prefiriendo a los "Quijotes de la Mancha" porque si bien eran "bo- 
tarates, atolondrados y locos", eran cristianos, y "hacían reír", en cambio los nuevos "nos hacen llorar". Para consuelo, España no requería de grandes disertaciones para combatir a socialistas y comunistas, con el Quijote era más que suficiente ([Fray Gerundio], 1849, pp. 205-213).

Es probable que la crítica cervantina a las costumbres marcadoras de jerarquías estuviera muy presente entre los intelectuales y constitucionalistas de la generación sanjuanista. El padre Velásquez fue señalado de practicar una quijotesca reforma en las costumbres de separación de calidades o castas, ya que en su mesa tomaba alimentos sin distinciones socioétnicas y sostenía reuniones igualitarias con los nuevos ciudadanos -indios- y no ciudadanos -afrodescendientes.

La crítica antisocialista era bien conocida en Yucatán cuando Sierra escribía sus "Consideraciones sobre el origen, causas y tendencias de la sublevación de los indígenas, sus probables resultados y su posible remedio", en El Fénix (noviembre de 1848-agosto de 1851). Más aún, al momento de narrar su disertación sobre el padre Velásquez en El Fénix del 29 de noviembre y 5 de diciembre de 1849, le imputó anacrónicamente que era un "verdadero socialista" como San Simón y Fourier, muy probable teniendo en mente a los "Quijotes" de antaño y hogaño.

\section{HUMOR PARA TIEMPOS DE GUERRA}

La prosa y la poética satírica comenzaron mucho antes de la aparición de los periódicos propiamente dichos en España y Yucatán. Durante la segunda etapa del liberalismo español en nuestra tierra, la prensa publicó diversos artículos burlescos bajo seudónimos caracterizados. Entre 1820 y 1821 tenemos a Pedro Perules y a Don Sancho El Bullicioso.

Pero en la cansada Europa de guerras y periódicos políticos, Modesto LaFuente propuso volver al Quijote para diversión y alegría (Fuertes, 2014, pp. 137-140). Ya Cervantes había prescrito el humor para "tiempos calamitosos" (Eisenberg, 1995). Prescripción emulada en la sociedad yucateca. El recurso del humor para el entretenimiento frente a tanta desgracia civil durante la década de los años cuarenta del siglo xix y el inicio de la guerra de castas, surgió con D. BulleBulle. Periódico Burlesco y de Extravagancias Redactado por una Sociedad de Bulliciosos (1847), por José Antonio Cisneros, José García Morales y Fabián Carrillo Suaste (Nini Moulin, Fabio y Fray Cleofás Pepín), y por 
supuesto Picheta. ${ }^{25}$ Carrillo dejó en su memoria los propósitos perseguidos: "servir a nuestra patria como escritores, atacando con vigor preocupaciones y demasías en las costumbres, en la administración pública, en la política, en la guerra y hasta en lo más respetable" (Carrillo, 1881, p. 163). Con D. BulleBulle hubo excesos, pero fue "necesario empaparlo en subido tinte para conseguir alguna enmienda de inveterados abusos, de rancias preocupaciones, de nuevas demasías y violencias en una sociedad que amenazaba hundirse" (p. 166); en especial para combatir la "perniciosa tendencia a las revueltas civiles" ${ }^{26}$

Pues bien, dicho periódico satírico inicia con una evocación a Cervantes y a los Viages de Enrique Wanton al país de las monas (1778), que pasó a citar: "En una isla, situada entre el Cabo Catoche y la Siberia, pero de cuyo nombre no queremos acordarnos, existía una república de monos, cuya historia, insípida al principio, hízose con el tiempo muy curiosa, principalmente desde que los tales monos de nuestra alma se privilegiaron de un modo bien extraño." 27

La referencia a Fray Gerundio en Carrillo es particularmente interesante, ${ }^{28}$ por su fuerte influjo cervantista, hasta emparentar a su personaje fray Cleofás Pepín con el primero mediante la hermandad de cuerpo religioso. ${ }^{29}$

En otro de sus relatos, Nini Moulin narró que en una noche de preparación de su artículo periodístico fue interrumpido por don Simplicio, que le hizo perder sus ideas. Bajo presión de entregar su original, el humorista fue desconcentrado por don Serapio, un teólogo pasante. A pesar de condicionar su visita a que le permitiera continuar su redacción, don Serapio rompió toda regla de cortesía y urbanidad escudriñando los libros:

${ }^{25}$ Pedro I. Pérez Ferrer y José María O'Horán abandonaron pronto la empresa. Pocas noticias se tienen de las obras de humor a fines de la colonia; posteriormente, surgieron autores costumbristas. Incluso la influencia cervantina se ha destacado en el uso del verso de cabo roto en Manuel Barbachano, también destacado costumbrista. Ruz Menéndez (1973, pp. 144 y ss.).

26 "Prólogo que con el título 'Dos palabras antes', fue expresamente escrito para una composición poética que en cuaderno suelto publicó Pedro Pérez Ferrer intitulada 'La Patria” (Carrillo, 1881, p. 171). Aunque Don BulleBulle apareció el 15 de abril de 1847 en el contexto de guerras civiles, aquí enfatizamos que Carrillo comprendiera la necesidad de hacer reír a la población afligida por la agonía, a causa de la sublevación indígena que estalló en julio de 1847. Reír de lo cómico, lo risible, no de la tragedia humana. Carrillo (1881, p. 314) y Esquivel Pren (1975, p. 39).

${ }_{27}$ "Introducción”, D. BulleBulle. Periódico Burlesco y de Extravagancias Redactado por una Sociedad de Bulliciosos, Mérida, s. d., s. m., 1847, p. 3.

28 "Aquí hay de todo", D. BulleBulle, s. d., s. m., 1847, p. 30. Carrillo (1881) reconoció no haber leído la obra de Modesto Lafuente cuando escribió la introducción del primer número del periódico (p. 166), aunque fray Gerundio fue mencionado en el artículo antes citado.

29 “Fray Pepín de misionero", D. BulleBulle, s. d., s. m., 1847, p. 104. 
¿Y aquel libro que está abierto sobre su asiento, cómo se titula?

Entonces tiro la pluma -relata Nini Moulin- y haciendo girar mi taburete sobre uno de sus pies traseros doy media vuelta. Me quedo mirando de hito en hito a don Serapio y con ungida serenidad le contesto:

-Es el Quijote.

-[j]Jesús, qué libro tan malo! Lleno de mentiras y necedades. Yo tuve el mío, flamante, pero lo cambié por los Doce pares de Francia. ${ }^{30}$ ¡Esa sí es obra de verdadera historia que me encanta!

Al oír tanta blasfemia contra Cervantes, poco me faltó para sacarle los ojos al muy animal, más todavía pude contener la expresión de la cólera que me estaba quemando las entrañas.

-Y... dime, ¿cómo se llama el autor de autor de aquel libro que también veo allá más lejos?

-Voltaire.

-¡María Purísima! Ése es aquel filósofo ruso...

-¡Cómo ruso!

-¡Inglés!

-Menos.

-Pues bien, haya sido del país que fuere: lo cierto es que es escritor infernal...

- ¿Ha leído usted sus obras?, dije levantándome, deseoso ya de armarle camorra al discípulo de Gotti y Lárraga.

-No, pero... le conozco muy bien, porque mi primo el cura Concentayna me ha asegurado que el tal ha hecho más daño a la iglesia que el padre Mahoma: ${ }^{31}$ bien que, a pesar detona su maldita filosofía, murió en la miseria, en el abandono y pidiendo muy arrepentido perdón de sus culpas al confesor...

-Esas son mentiras muy groseras y muy ridículas que han querido propagar las gentes a que él arrancó la máscara [...], me incomoda e irrita el que la ignorancia apoyada en la mentira y la calumnia dé saltos de enano por coger y estrujar entre sus manos sucias los laureles inmortales que ciñen la frente del genio. $^{32}$

30 Se comprende la ironía de cambiar el Quijote por un libro de caballerías de Nicolás de Piemonte, Historia del emperador Carlo Magno y de los doce pares de Francia de 1549.

${ }^{31}$ En esta situación, el autor del relato de humor traza la actitud adecuada de consultar $y$ seguir las recomendaciones de autoridad para desechar las malas lecturas.

${ }^{32}$ Nini Moulin, "Los importunos", D. BulleBulle, s. d., s. m., 1847, pp. 305-306. 
Luego de aquellos episodios de zozobra y Don BulleBulle, Carrillo concluyó sus escritos de humor en La Linterna (1850-1852). El comportamiento de Silverio Colmenares, un amigo imaginario, que vendió algunos terrenos y abandonó cultivos para adquirir ropaje de moda y dedicarse a la política, trajo a colación la locura de don Quijote por enajenar "sus tierras de labor para comprar libros de caballería con qué empaparse el cerebro" (Carrillo, 1881, p. 344). Las fuentes de la insania de don Quijote, los libros de caballería, fueron sustituidas por un cuento: gastar en las prácticas del clientelismo electoral (comidas, músicas, regalos, etc.), con la oferta de avanzar en posiciones hasta alcanzar cargos de elección, con sus respectivas compensaciones. La credulidad de Silvestre le condujo a perseguir un futuro de humo, una ilusión; y a Nini Moulin le reforzó la creencia en la verosimilitud del Quijote.

Años más tarde, Carrillo (1881) volvía a su fuente de inspiración: "Aconsejado yo por mí mismo, como lo fue el Hidalgo de la Mancha para resucitar la caballería andante", iniciaba el proyecto de reimprimir sus publicaciones (p. [5]). El Quijote fue algo más que una referencia y patrón de explicación, a posteriori Carrillo (1881) consideró excesivo asumir que su obra podría "reanimar el espíritu literario", a la manera de su héroe, y con humor dijo esperar un Cervantes para escribir su chistosa historia (p. 7).

\section{EPÍLOGO: UNA LECTURA INÚTIL}

Las lecturas del Quijote como una obra de humor y novela ejemplar prevalecieron hasta mediados del siglo XIX, aquilatadas por su valor monumental y clásico de las letras hispánicas. Moreno rechazó que el caballero de la Mancha fuera un héroe clásico, sino un hombre enojado y trastornado, pero de un desprendimiento absoluto. Ridículo pero simpático, un juicio similar al de $E l$ Censor de Madrid (1785). Pero en el plano de la realidad, en el contexto de una sociedad amenazada con el exterminio en manos de los indígenas rebeldes, no todos los locos resultaron de imaginación, ni fueron tan "poco perjudiciales” (como Ríos y el padre Zúñiga), sino verdaderos locos de atar.

El Quijote fue un recurso para el discurso histórico, el debate político y el humor. En Sierra fue modelo para construir personajes, cuyas locuras afloraron de proyectar errores, fábulas y extravagancias (de la Leyenda Negra de la Conquista) a la realidad. Pero desmanteló el efecto simpático e inofensivo de las locuras quijotescas para revelar que aquellos locos, por suspensión del 
juicio crítico y la "lógica en lo absurdo", perseguían utopías perniciosas para el establishment. En el discurso histórico no se trataba de motivar risa, sino antipatía hacia los defensores y agitadores de la masa indígena. En contraparte, Don Quijote fue referente e inspirador del humor para relajar a una sociedad blanca al borde del exterminio y cambiar costumbres. Pero en la política fue referente para la burla pública y hostigamiento hacia los "humanistas", defensores de los indígenas. En ese mismo contexto de crisis, el socialismo y el comunismo fueron nuevas utopías entendidas bajo el modelo de la locura quijotesca persiguiendo fantasías, pero nada jocosas ya que movían al llanto.

A mediados de los años cincuenta del siglo xix, la lectura del Quijote dejó de ser recomendable a raíz de los criterios de la literatura moderna, ${ }^{33}$ un vehículo de transmisión de diversos conocimientos y valores dirigidos al mejoramiento de la sociedad. Leer por diversión sin ningún aprendizaje ya no era apreciado, sino menospreciado como una pérdida de tiempo, vana ocupación del hombre "semicivilizado" con gustos por las fantasías, aventuras de caballerías, hadas, etc. En opinión de Juan A. Esquivel, aquel tipo de lectura no era más que una actividad "estéril remedo de las preocupaciones vulgares", sin objeto útil, ni argumento de triunfo de una idea moral, mucho menos trataba, por su desconocimiento, del hombre y la naturaleza, tan sólo "apoteosis de la locura" en tiempos bárbaros. ${ }^{34}$ La crítica de Esquivel apuntó hacia la obra de Cervantes, de cuya imaginación salió un héroe que "desapareció de la escena literaria" envuelto de rechiflas y risas que excitaron sus "ridículas aventuras". ${ }^{35}$

Esquivel reconoció la importancia de aquella "obra monumental", que durante tres siglos fue modelo de la sátira y de los escritos de "costumbres con las puntas del sarcasmo", pero en seguida cuestionó: “¿Mejoró con esto la novela? ¿Alcanzó aunque fuese un lugar nada preminente entre los escritos útiles? ¿Se había granjeado algo con aquella regeneración? [...] Continuó resintiéndose de la misma esterilidad [...]. Después de leer una novela escrita en aquella época, se experimenta recreo; más el entendimiento nada saca de provecho. Es una verdad." ${ }^{36}$

${ }^{33}$ Juan A. Esquivel, "La novela”, El Pensamiento, s. d., s. m., 1856, pp. 47-48. El artículo fue reproducido en La Guirnalda. Periódico Literario, Mérida, s. d., s. m., 1861, pp. 49-50.

${ }^{34}$ Juan A. Esquivel, "La novela", El Pensamiento, s. d., s. m., 1856, pp. 46-47.

${ }^{35}$ Juan A. Esquivel, "La novela”, El Pensamiento, s. d., s. m., 1856, p. 47.

${ }^{36}$ Juan A. Esquivel, "La novela", El Pensamiento, s. d., s. m., 1856, p. 47. 
En cambio, Esquivel apreciaba la novela histórica y la romántica que gozaban de gran popularidad y "más a propósito para la propagación de las ideas". Asimismo, resaltaba las virtudes de la novela social por entrañar conocimientos útiles, filosóficos, positivos y morales. Pero despreciaba el exceso que, a pretexto de la abyección de algunas clases, se atentase contra los principios sagrados de la sociedad: la familia, la propiedad, la religión y el patriotismo. Este género de novela tomaba como argumento un problema social, pero en la solución describía utopías y "doctrinas ponzoñosas" como el socialismo. De ese modo, la novela social retrogradaba a los "tiempos de caballería", es decir, a la inverosimilitud. ${ }^{37}$

¿Qué tanto afectó la crítica instrumental a la popularidad de Don Quijote?, ¿se encontraba disponible en bibliotecas públicas de mediados del siglo XIX? En las de Mérida no podemos responder debido a la pérdida de sus catálogos, pero a fines de 1861, en el gabinete de Campeche fue una de las ausencias más notables. El Quijote seguía expendiéndose de manera esporádica en librerías y comercios meridanos. Sabemos que no formaba parte del Catálogo de la Librería Meridana de 1857; fue hasta 1861 que ofertó una edición de gran lujo, con láminas ilustradas en dos volúmenes, y en 1866 anunció: "Cervantes. El Ingenioso Hidalgo D. Quijote de la Mancha, según el texto corregido y anotado por el Sr. Ochoa, 4 t. Lujosamente encuadernado y cortes dorados. [A un precio de 4 pesos]" (Librería Meridana de Cantón, 1866-1867, p. 13).

Se trataba de la edición americana de 1860 realizada en Nueva York, por D. Appleton y Compañía (Cervantes, 1860). Un año antes, en 1865, Manuel Pío del Castillo se había dirigido a los hacendados para ofrecerles Don Quijote de la Mancha, entre otros libros. ${ }^{38}$

Más allá de la polémica sobre la utilidad de la obra como "libro moral", más que de entretenimiento y risa (de acuerdo a Clemencín), o de puro recreo sin progreso para el entendimiento, el humor dejó de percibirse como vehículo idóneo para estimular el cambio de costumbres. A pesar de ello, algunos literatos yucatecos continuaban reivindicando el humor de Don Quijote y su impacto reformador en las costumbres de su época. En 1861, Eligio Ancona observó esa paradoja: “[j]Ay! [j]No todos -los literatos- tienen el talento ni la

37 Juan A. Esquivel, "La novela”, El Pensamiento, s. d., s. m., 1856, p. 48. Sol (2014) ha revelado la importancia de lo facticio y el anclaje en la historia de las novelas de Sierra (pp. 17-18, 35-39).

${ }_{38}$ M. Pío del Castillo. Intesante [sic] a los hacendados. La Oliva. Periódico de Literatura y Variedades Redactado por E. Mac-Kinney, Mérida, 12 de marzo de 1865, s. n. 
suerte de Cervantes para desterrar con un rasgo de su pluma una preocupación ridícula o un defecto pernicioso!" ${ }^{9} 9$ De hecho, Carrillo (1881) recurrió a su héroe al mirar en retrospectiva el "fracaso de su empresa" (p. 7), entendible sólo en cuanto a la misión de reformar costumbres y combatir credulidades/ incredulidades.

\section{LISTA DE REFERENCIAS}

Calero, V. (1845). Literatura. Artículo I. Reflexiones sobre la novela. En Registro Yucateco. Periódico Literario (vol. 1, pp. 64-70). Mérida: Imprenta de Castillo y Compañía. Carrillo Suaste, F. (1881). La colección literaria. Obras publicadas y otras inéditas del doctor [...]. Mérida: Imprenta del Comercio a cargo de Ignacio L. Mena.

Castro Ibarra, G. (2004). Justo Sierra O'Reilly: pionero de la novela histórica y de folletín en México. Caleidoscopio, 16, 125-135. DoI: https://doi.org/10.33064/16crscsh507

Cervantes, M. (1608). El ingenioso hidalgo don Quixote de la Mancha. Compuesto por Miguel de Cervantes. Madrid: por Iuan de la Cuesta.

Cervantes, M. (1615). Segunda parte del ingenioso cavallero don Qvixote de la Mancha. Madrid: por Iuan de la Cuesta.

Cervantes, M. (1780). El ingenioso hidalgo don Quixote de La Mancha. Nueva edición corregida por la Real Academia Española. Con superior permiso (4 vols.). Madrid: por don Joaquín Ibarra Impresor de Cámara de S. M. y de la Real Academia.

Cervantes, M. (1797). El ingenioso hidalgo don Quixote de la Mancha. Compuesto por Miguel de Cervantes Saavedra. Nueva edición corregida de nuevo, con nuevas notas, con nuevas estampas, con nuevo análisis, y con la vida de el autor nuevamente aumentada por $D$. Juan Antonio Pellicer Bibliotecario de S. M. y académico de número de la Real Academia de la Historia (4 vols.). Madrid: por D. Gabriel de Sancha.

Cervantes, M. (1799). Novelas exemplares de Miguel de Cervantes Saavedra. Madrid: Imprenta de Villalpando.

Cervantes, M. (1833). El ingenioso hidalgo don Quijote de la Mancha, compuesto por Miguel de Cervantes Saavedra, y comentado por don Diego Clemencin (2 vols.). Madrid: en la Oficina de D. E. Aguado, Impresor de Cámara de S. M.

Cervantes, M. (1842). El ingenioso hidalgo don Quijote de la Mancha, por Miguel de Cervantes Saavedra. Obra adornada de 125 estampas litográficas y publicada por

${ }^{39}$ E. Ancona, "No hay peor cuña”. Álbum Yucateco, Periódico Literario. Mérida, s. d., s. m., 1861, p. 41. 
Masse y Decaen, impresores litógrafos y editores (2 vols.). México: Impreso por Ignacio Cumplido.

Cervantes, M. (1860). El ingenioso hidalgo don Quijote de la Mancha. Según el texto corregido y anotado por el Sr. Ochoa. Nueva edición americana acompañada de un ensayo histórico sobre la vida y escritos de Cervantes (4 vols.). Por el Dr. Jorge Ticknor. Nueva York: D. Appleton y Compañía.

Cervantes, M. (2005). Don Quijote de la Mancha. Edición del IV Centenario. Madrid: Real Academia Española/Asociación de Academias de la Lengua Española.

Eisenberg, D. (1995). La interpretación cervantina del Quijote. Delaware: Compañía Literaria. Recuperado de https://users.ipfw.edu/jehle/deisenbe/interpret/ICQcap3. htm

El Censor (1785). Discurso LXVIII, 1785. En A. Rey Hazas y J. R. Muñoz Sánchez (eds.), El nacimiento del cervantismo: Cervantes y el Quijote en el siglo XVIII (pp. 387-394). Madrid: Editorial Verbum.

Esquivel Pren, J. (1975). Historia de la literatura en Yucatán. T. 8: Los novelistas del siglo XIX. Las sociedades literarias del siglo XIX. México: Ediciones de la Universidad Autónoma de Yucatán.

Fuertes Arboix, M. (2014). La sátira política en la primera mitad del siglo XIX: Fray Gerundio (1837-1842) de Modesto Lafuente. San Vicente del Raspeig: Publicaciones de la Universidad de Alicante.

[Fray Gerundio] (1848). El Quijote de Antaño, y los quijotes de ogaño. Revista Europea, por don Modesto La Fuente (t. 1, pp. 387-395). Madrid: Tipografía de Mellado.

[Fray Gerundio] (1849). El Quijote de antaño, y los quijotes de ogaño. En Miscelánea instructiva y amena. Colección escogida de escritos sobre todas materias, en prosa y en verso, originales, copiados y traducidos (vol. 2, pp. 200-213). Mérida: Oficina Tipográfica de Rafael Pedrera.

Gómez Álvarez, C. (2011). Navegar con libros. El comercio de libros entre España y Nueva España (1750-1820). México: UNAM/Trama Editorial.

Guzmán y Manrique J. (1778). Viages de Enrique Wanton a las tierras incógnitas australes, y al País de las Monas: en donde se expresan el carácter, ciencias, costumbres de estos extraordinarios habitantes (2 vols.). Madrid: [por d. Antonio Sancha].

Hagedorn, H. G. (2007). Prólogo. En H. G. Hagedorn (coord.), Don Quijote por tierras extranjeras (pp. 11-28). Cuenca: Ediciones de la Universidad de Castilla-La Mancha.

Lara Zavala, H. (2005). Justo Sierra O'Reilly. El hombre de letras. En B. Clark de Lara y E. Speckman Guerra (eds.), La república de las letras. Asomos a la cultura escrita del México decimonónico. Vol. III: Galería de escritores (pp. 149-161). México: unAm. 
Librería Meridana de Cantón (1866-1867). Catálogo de los libros que se hallan de venta en la Librería Meridana de Cantón. Mérida: s. e.

Moreno, P. (1841). Algunas observaciones críticas sobre el Quijote. En Museo Yucateco. Periódico Científico y Literario (vol. 1, pp. 251-254). Campeche: Impreso por José María Peralta.

Rey Hazas, A. y Muñoz Sánchez, J. R. (2006). Estudio preliminar. En A. Rey Hazas y J. R. Muñoz Sánchez, El nacimiento del cervantismo: Cervantes y el Quijote en el siglo XVIII (pp. 13-87). Madrid: Editorial Verbum.

Ríos, V. de los (1780). Análisis del Quixote. Artículo primero. Principios en que se funda este análisis. En M. Cervantes, El ingenioso hidalgo don Quixote de la Mancha (pp. XLIV-CLII). Madrid: Joaquín Ibarra Impresor.

Riquer, M. (2005). Cervantes y el Quixote. En M. Cervantes, Don Quijote de la Mancha (pp. XLV-LXXv). Madrid: Real Academia Española/Asociación de Academias de la Lengua Española.

Rivero Iglesias, C. (2011). La interpretación idealista del Quijote. En C. Rivero Iglesias (ed.), Ortodoxia y heterodoxia en Cervantes (pp. 381-396). Alcalá de Henares: Ediciones del Centro de Estudios Cervantinos.

Ruz Menéndez, R. (1973). Los versos de cabo roto de don Manuel Barbachano y Tarrazo. En R. Ruz Menéndez, Por los viejos caminos del Mayab... Ensayos históricos y literarios (pp. 133-154). Mérida: Ediciones de la Universidad de Yucatán.

Ruz Menéndez, R. (1992). El cervantismo en Yucatán. En C. Bojórquez Urzaiz, R. Ruz Menéndez y C. Urzaiz Jiménez, Cervantes en Yucatán (pp. 25-41). Mérida: Ediciones de la Universidad Autónoma de Yucatán.

Sánchez-Blanco, F. (2002). El Absolutismo y las Luces en el reinado de Carlos III. Madrid: Marcial Pons.

Sierra O’Reilly (1841). Noticia biográfica de D. Pablo Moreno. En Museo Yucateco (vol. 1, pp. 16-20). Campeche: Impreso por José María Peralta.

Skirius, J. (1982). Fernández de Lizardi y Cervantes. En Nueva Revista de Filología Hispánica, 31(2), 257-272.

Sociedad de Amigos (1860). Ligeras apuntaciones que una sociedad de amigos dedica al NUEVo Don QUiJote aparecido en estos días sosteniendo los derechos no ultrajados de Yucatán. Mérida: Imprenta de Rafael Pedrera.

Sol, M. (2014). Introducción. En J. Sierra O’Reilly, Un año en el hospital de San Lázaro (pp. 15-64). Xalapa: Universidad Veracruzana.

Turrisa, J. (1841). Profetas. En Museo Yucateco. Periódico Científico y Literario (vol. 1, pp. 2-8). Campeche: Impreso por José María Peralta. 
Wardropper, B. W. (1984). Don Quijote: ¿ficción o historia? En G. Haley (ed.), El Quijote de Cervantes (pp. 237-252). Madrid: Taurus. Recuperado de https://cvc.cervantes.es/literatura/quijote_antologia/wardropper.htm

\section{OTRAS FUENTES}

\section{Hemerografía}

D. Bullebulle, Mérida, 1847.

El Amigo del Pueblo, Campeche, 1847.

El Constitucional, Mérida, 1861.

El Pensamiento, Mérida, 1856.

El Yucateco o El Amigo del Pueblo, Mérida, 1821.

La Guirnalda, Mérida, 1861.

La Oliva, Mérida, 1865.

Miscelánea Instructiva y Amena, Mérida, 1849.

Museo Yucateco, Campeche, 1841.

Registro Yucateco, Mérida, 1845, 1846. 